\title{
Mental Health and Academic Achievement of College Students
}

\author{
Dr. Shashi Kala Singh ${ }^{1}$
}

\section{ABSTRACT}

The present study aimed at examining the impact of mental health on academic achievement of college students. For this purpose 200 college students (100 males \& 100 females) were selected from different colleges of Ranchi town. The marks obtained in class XII ${ }^{\text {th }}$ of Central Board of Secondary Education was used as the indicator of academic achievement. Students were classified into two groups namely high achiever (who obtained above 65\% marks) and low achiever (who obtained below 50\% marks). The data was collected by Mental Health Battery which was developed by Arun Kumar Singh and AlpnaSen Gupta.The result showed that male, group was mentally healthy than female group. High achiever group was mentally healthy than low achiever group. Mental health was positively related with academic achievement.

Keywords: Mental Health, Academic Achiever, High Academic and Low Academic Achiever

Mental Health is the balanced development of the individual's personality and emotional attitudes which enable him to live harmoniously with his/her fellow men/women. Mental health is a state of well-being in which an individual realizes his or her own abilities, can cope with the normal stresses of life, can work productively and is able to make a contribution to his or her community. In this positive sense, mental health is the foundation for individual well-being and the effective functioning of a community. Mental health promotion requires multi-sect oral action, involving a number of government sectors and non-governmental or community-based organizations. The focus should be on promoting mental health throughout the lifespan to ensure a healthy start in life for children and to prevent mental disorders in adulthood and old age.

Mental health is emotional, behavioral, and social maturity or normality; the absence of a mental or behavioral disorder; a state of psychological well-being in which one has achieved a satisfactory integration of one's instinctual drives acceptable to both oneself and one's social milieu; an appropriate balance of love, work, and leisure pursuits. According to WHO (World Health Organization), mental health is "a state of well-being in which the individual realizes his or her own abilities, can cope with the normal stresses of life, can work productively and fruitfully, and is able to make a contribution to his or her community". WHO stresses that mental health "is not just the absence of mental disorder".

${ }^{1}$ Associate Professor, Dept. of Psychology, Ranchi University, Ranchi

(C) 2015 I S Singh; licensee IJIP. This is an Open Access Research distributed under the terms of the Creative Commons Attribution License (http://creativecommons.org/licenses/by/2.0), which permits unrestricted use, distribution, and reproduction in any Medium, provided the original work is properly cited. 
Mental health depends upon biological and social factors, its transient and not the static in nature. Mental health is a complete of physical, mental and social well-being and not merely absence of the disease or infirmity. It involves Emotional stability Over-all adjustment, Autonomy, Security-Insecurity, Self-concept, Intelligence.

- Emotional stability-It refers to experiencing subjective stable feelings which have positive or negative values for the individual.

- Adjustment- It refers to individual's achieving an overall harmonious balance between the demands of various aspects of environment, such as home, health, social, emotional and school on the one hand and cognition on the other.

- Autonomy- It refers to a stage of independence and self-determination in thinking.

- Security-Insecurity- It refers to a high (or low) sense of safety, confidence, and freedom from fear, apprehension or anxiety particularly with respect to fulfilling the person's present or future needs.

- Self-concept- It refers to the sum total of the person's attitudes and knowledge towards himself and evaluation of his achievements.

- Intelligence- It refers to general mental ability which helps the person in thinking rationally and in behaving purposefully in his environment.

A Mentally healthy person shows a homogeneous organization of desirable attitudes, healthy values and righteous self-concept and a scientific perception of the world as a whole. Mental Health is a condition of psychological maturity - are relatively constant and enduring function of personality. It is a condition of personal and social functioning with a maximum of effectiveness and satisfaction. Mental Health involves positive feelings and attitudes toward the self and toward others. The World Health Organization defines mental health as "a state of well-being in which the individual realizes his or her own abilities, can cope with the normal stresses of life, can work productively and fruitfully, and is able to make a contribution to his or her community" (WHO, 2005).

According to the President's New Freedom Commission on Mental Health (2003), approximately 5-9\% of children have a "serious emotional disturbance." This term refers to any diagnosable mental disorder (in a child under age 18) that severely disrupts social, academic, and emotional functioning. This means that in our schools, there are one to two children in every classroom who are suffering from a serious mental disability, yet nearly $80 \%$ of these children do not receive the mental health services they require. According to the Department of Education, $50 \%$ of children with serious emotional/ behavioral disorders drop out of high school, compared to $30 \%$ of students with other disabilities - making it the highest drop-out rate of any disability group. A 2005 study by Miech and colleagues provides more evidence that the educational disparities caused by mental illness persist through life. This longitudinal study assessed mental health status and educational attainment of over 1,000 general population subjects in 1981 and again 13 years later. Those who did not complete high school were more likely to have 
symptoms of mental illness at both points in time compared to those who did complete high school. study carried out at a school-based health center (SBHC) of a public high school with a large population of low-income and Hispanic students (Gall et al., 2000) showed that students with mental health problems had a much higher rate of absenteeism, tardiness, and lower grades than those without mental health problems.

Academic achievement or (academic) performance is the outcome of education - the extent to which a student, teacher or institution has achieved their educational goals. Academic achievement is commonly measured by examinations or continuous assessment but there is no general agreement on how it is best tested or which aspects are most important - procedural

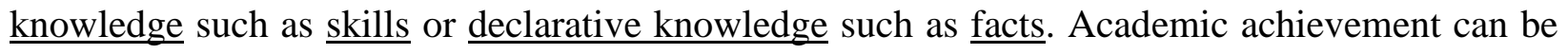
defined as excellence in all academic disciplines, in class as well as extracurricular activities. It includes excellence in sporting, behaviour, confidence, communication skills, punctuality, assertiveness, Arts, Culture, and the like. Academic achievement is among the most thoroughly studied social consequences of mental health problems. Most studies come from outside the sociology of mental health, especially from sociology of education, social epidemiology, and developmental psychology (e.g., Campbell \& Von Stauffen berg, 2007). These studies find that youth with mental health problems perform less well in school and attain lower levels of education than other youth. The association holds throughout the early life course-in elementary school (e. g. , Alexander, Entwisle, \& Dauber 1993; Farmer \& Bierman 2002), Several investigators (Chopra, 1968; Cronback \& Furby, 1970; Deo Mohan, 1972; Jesudason, 1979; Kothurkar, 1962;Mahale, 1975;Pandey, 1973; \& Singh, 1965; etc.) have used examination marks as indicator of academic achievement in some form or the other.

\section{HYPOTHESES}

There will be no significant gender differences in mental health among college students.

$>$ There will be significant differences in mental health among college students with high and low academic achievement.

$>$ There will be positive relationship between mental health and academic achievement.

\section{SAMPLE}

A sample of 200 adolescents, who studying in B.A part I, different colleges of Ranchi town (Jharkhand, India) selected on stratified random basis for the present study. The stratification was based on gender (Male \&Female) and level of achievement (High achievers and Low achievers).High achievers, who obtained marks above $65 \%$ and low achievers who obtained marks below $50 \%$ in their $12^{\text {th }}$ class examination.

\section{TOOLS}

1. Mental Health Battery (MHB):-In the study the investigator employed English version of Mental HealthBattery which was developed and validated by Arun Kumar Singh and AlpanaSen Gupta (1971). Mental Health Battery intends to assess the status of mental health 
of persons in the age range of 13 to 22 years. As it is a battery of six tests. There are set of 130 items in the Mental Health Battery with six dimensions-emotional stability (ES), over all adjustment (OA), Autonomy (AY), security - Insecurity (SI), self -concept (SC) and Intelligence (IG. The reliability coefficient of the scale is ranged from .12 to .88 and the validity coefficient of the scale is ranged from .60 to .82 .

2. Academic Achievement: -In the present investigation academic achievement constitutes the aggregate marks obtained by the subjects in their $12^{\text {th }}$ class examination.

\section{PROCEDURE}

Mental Health Battery was administered to the students. Data was collected and scoring was done with the help of scoring key. Means and SDs were calculated for Mental Health Battery Score. Comparison was made by applying ' $t$ ' test. To find out the relationship between academic achievement and mental health product moment correlation coefficient was computed.

\section{RESULT AND DISCUSSION}

The obtained data were analysed with the help of Means, SDs and' $t$ ' test. Table -1 presented a comparison of the Male and Female adolescents on Mental Health.

The result of the present study shows that male and female group differed significantly from each other in the six areas of mental health battery (Emotional Stability, Overall Adjustment, Autonomy, Security-Insecurity, Self-Concept and Intelligence).. Which indicate that male group have better mental health than female group. Male students has greater level of Emotional Stability, better adjustment level, more sense of security, Self-concept, more intelligent and better Overall mental health than female students.

Thus the hypothesis "There will be no significant gender differences in mental health among college students" is rejected.

Table 1 -Means, SDs and' $t$ ' values of male and female adolescents on mental health

\begin{tabular}{|l|l|l|l|l|l|l|l|l|l|}
\hline \multirow{2}{*}{ Sr.No } & \multirow{2}{*}{ Factor } & \multicolumn{3}{|l|}{ Male } & \multicolumn{3}{l}{ Female } & \multirow{2}{*}{ 't' } & P VALUE \\
\cline { 2 - 10 } & Mean & SD & N & Mean & SD & N & & \\
\hline 1. & $\begin{array}{l}\text { Emotional } \\
\text { Stability }\end{array}$ & 17.85 & 4.62 & 100 & 15.94 & 3.96 & 100 & 3.18 & 0.01 \\
\hline 2. & $\begin{array}{l}\text { Overall } \\
\text { Adjustment }\end{array}$ & 29.86 & 4.28 & 100 & 26.43 & 3.83 & 100 & 6.12 & 0.01 \\
\hline 3. & Autonomy & 9.59 & 2.01 & 100 & 8.26 & 1.38 & 100 & 6.04 & 0.01 \\
\hline 4. & $\begin{array}{l}\text { Security } \\
\text { Insecurity }\end{array}$ & 7.76 & 2.62 & 100 & 6.31 & 2.04 & 100 & 4.67 & 0.01 \\
\hline 5. & Self-Concept & 11.63 & 2.53 & 100 & 9.81 & 2.26 & 100 & 5.51 & 0.01 \\
\hline 6. & Intelligence & 16.21 & 4.06 & 100 & 13.84 & 3.28 & 100 & 4.74 & 0.01 \\
\hline & $\begin{array}{l}\text { Total Mental } \\
\text { Health }\end{array}$ & 106.31 & $\begin{array}{l}10.2 \\
1\end{array}$ & 100 & 99.73 & 9.64 & 100 & 4.70 & 0.01 \\
\hline
\end{tabular}


Figure -1, Mean scores, of male and female of mental health.

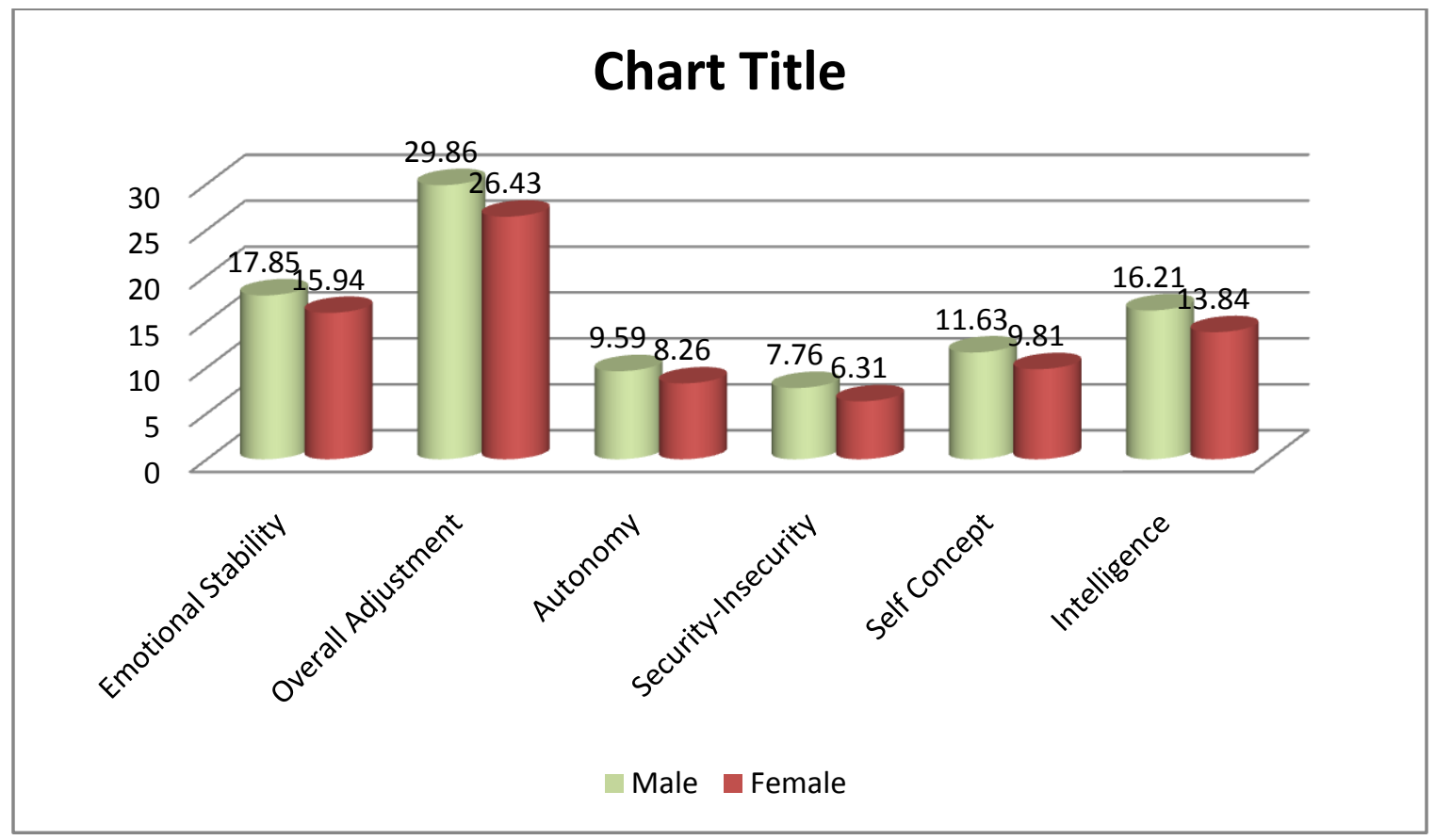

The obtained data were analyzed with the help of Means, SDs and ' $t$ ' test. Table -2 presented a comparison of the high and low achiever on Mental Health. High achieving group scored higher $(\mathrm{M}=106.31)$ than Low achieving college students $(\mathrm{M}=99.73)$ on mental health battery. All category of high achieving group secured higher mean scores on mental health battery than low achieving group. It indicates that high achievers were more mentally healthy than low achiever. All the' $t$ 's were highly significant at 0.01 level.

Thus the hypothesis "There will be significant differences in mental health among college students with high and low academic achievement" is accepted. 
Table 2 -Mean scores, SDs and't' values of high and low achievers of mental health.

\begin{tabular}{|c|c|c|c|c|c|c|c|c|c|}
\hline \multirow{2}{*}{$\begin{array}{l}\text { Sr.N } \\
\text { o }\end{array}$} & \multirow[b]{2}{*}{ Factor } & \multicolumn{3}{|c|}{ High Achiever } & \multicolumn{3}{|c|}{ Low Achiever } & \multirow[b]{2}{*}{ 't' } & \multirow[b]{2}{*}{ P VALUE } \\
\hline & & Mean & SD & $\mathbf{N}$ & Mean & SD & $\mathbf{N}$ & & \\
\hline 1. & Emotional Stability & 16.57 & 4.41 & 100 & 14.39 & 3.24 & 100 & 4.11 & 0.01 \\
\hline 2. & Overall Adjustment & 28.53 & 4.13 & 100 & 27.48 & 3.08 & 100 & 2.10 & 0.05 \\
\hline 3. & Autonomy & 10.08 & 2.36 & 100 & 8.12 & 1.84 & 100 & 6.32 & 0.01 \\
\hline 4. & Security - Insecurity & 8.72 & 3.06 & 100 & 7.02 & 2.54 & 100 & 4.47 & 0.01 \\
\hline 5. & Self-Concept & 12.76 & 2.86 & 100 & 10.91 & 2.47 & 100 & 5 & 0.01 \\
\hline 6. & Intelligence & 17.48 & 4.16 & 100 & 15.06 & 3.08 & 100 & 4.84 & 0.01 \\
\hline \multicolumn{2}{|c|}{ Total Mental Health } & $\begin{array}{l}107.8 \\
6\end{array}$ & $\begin{array}{l}10.5 \\
4\end{array}$ & 100 & 98.46 & 9.26 & 100 & 6.71 & 0.01 \\
\hline
\end{tabular}

Figure-2, Mean scores of high and low achievers of mental health.

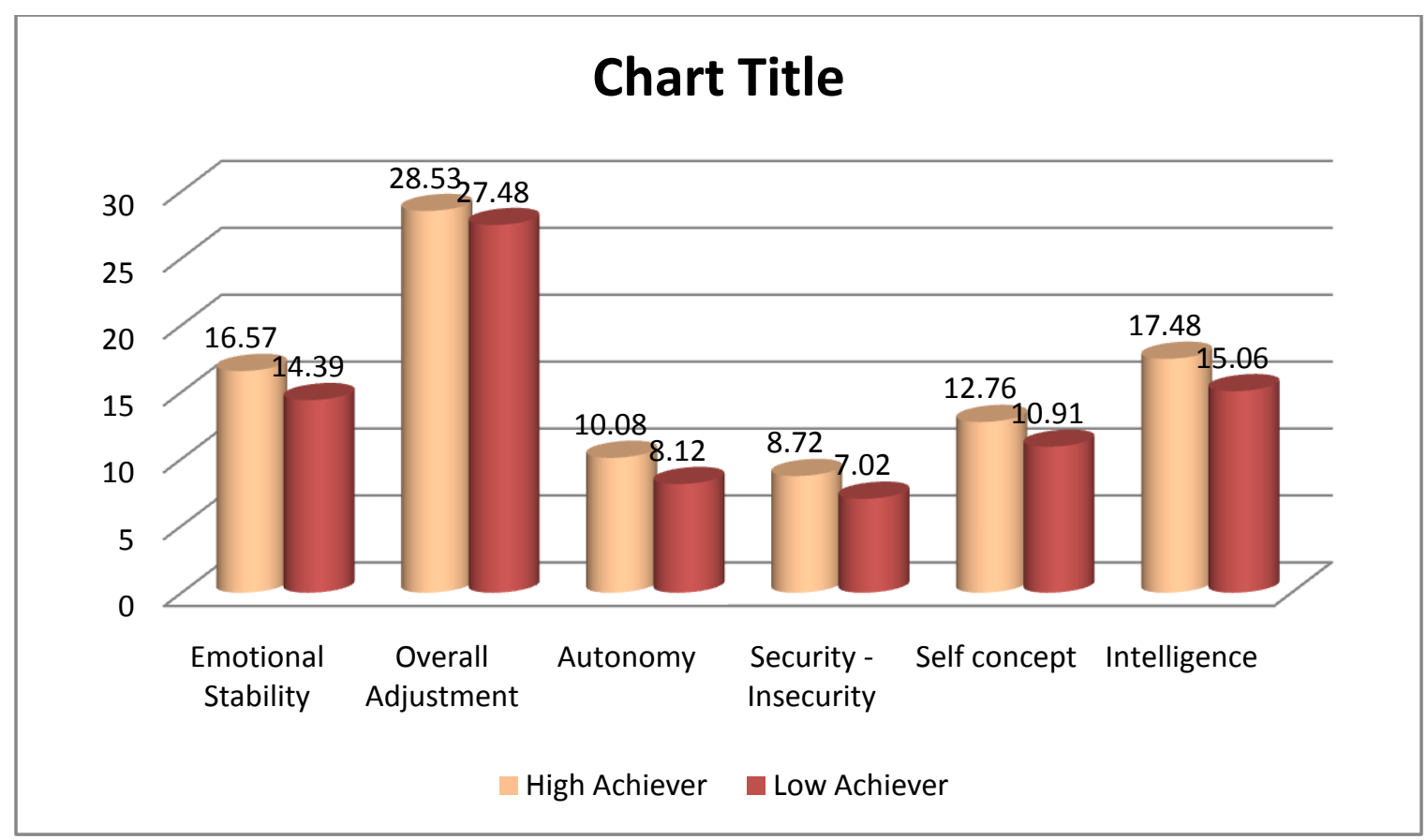


Using product moment method of coefficients of correlation, an attempt was made to explore the relationship of academic achievement with mental health.

Table 3, Correlation coefficient between Academic Achievement and Mental Health.

\begin{tabular}{|l|l|l|}
\hline $\mathbf{N}$ & $\mathbf{r}$ & P Value \\
\hline 200 & 0.4251 & 0.01 \\
\hline
\end{tabular}

It is obvious from the table 3 that academic achievement and mental health exists positive correlation which was significant at 0.01 levels. Thus the hypothesis "There will be positive relationship between mental health and academic achievement" is accepted. This indicated that a person with having high academic achievement tend to score high and person having low academic achievement tend to scores low on the scale of Mental Health. Kasinath (2003) revealed that there is a significant effect of mental health on academic achievement.

\section{CONCLUSIONS}

(1) Male group have better mental health than female group.

(2) High and Low achiever differs significantly in their mental health.

(3) Mental Health is positively and significantly co-related with academic achievement.

\section{REFERENCES}

Alexander, Karl. L., Doris. R. Entwisle, \& Susan L. Dauber. (1993). "First Grade Classroom Behavior: Its Short- and Long-Term Consequences for School Performance." Child Development 64:801-14.

Campbell, Susan. B \& Camilla von Stauffenberg. (2007). "Child Characteristics and Family Processes that Predict Behavioral Readiness for School”. 225-58 in Disparities in School Readiness: How Families Contribute to Transitions into School, edited by A. Booth.

Chopra, S. L. (1968).Measured intelligence and academic achievement as related to urban and rural residence. Rural Sociology.33 (2), 214 - 217.

Cronback. L. J. \& Furby. L. (1970). How we should measure change Or should we. Psychological Bulletin.74, 68 - 80.

Deo, P.\& Mohan, A. (1972). Patterns of academic achievement. Indian Educational Review.7 (2), $101-116$.

Farmer, Alvin, D \& Karen L.Bierman.(2002). "Predictors and Consequences of AggressiveWithdrawn Problem Profiles in Early Grade School.”Journal of Clinical Child and Adolescent Psychology 31: 299-311. 
Gall. G, Pagano. M, Desmond. S, Perrin. J \& Murphy. J.M. (2000). Utility of psychosocial screening at a school-based health center. The Journal of School Health. 70(7):292-298.

Jesudason.V. (1979).Indian students in the United States, Socio - economic background, academic performance and plans to return home. Indian Educational Review.14 (1), 1 21.

Kasinath.(2003).Home Environment, Mental Health and Academic Achievement among Hr. Secondary School Students. Journal of Education and Practice. Vol -1 (1),1-7.

Kothurkar, V. K. (1962). Psychological survey of secondary school children of Poona. University of Poona.

Mahale, M.N. (1975).Family situation and the education of the adolescent. Unpublished .Ph.D.Thesis. Bombay University, Bombay.

Miech. R.A, Eaton. W.W.\& Brennan. K. (2005). Mental health disparities across education and sex: a prospective analysis examining how they persist over the life course. The Journals of Gerontology Series B: Psychological Sciences and Social Sciences. 60(2):93-8

Pandey, R.P. (1973).Unpublished. Ph.D.Thesis. L.N.M.U. Darbhanga.

President's New Freedom Commission on Mental Health. (2003). Achieving the Promise: Transforming Mental Health Care in America. Final Report. DHHS Pub. Rockville, MD.

Singh, B. K. (1965). Some non - intellectual correlates of academic achievement. Unpublished Ph.D. Thesis. Patna University, Patna. 